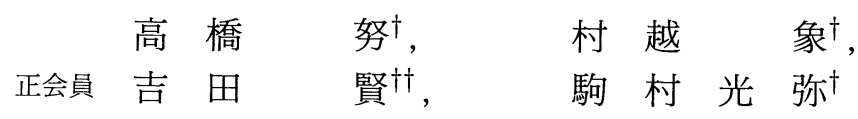

\title{
Adaptive Quantizer to Shape of Amplitude Distribution in Subband Coding
}

Tsutomu Takahashi ${ }^{\dagger}$, Sho Murakoshi ${ }^{\dagger}$, Masaru Yoshida $^{\dagger \dagger}$ and Mitsuya Komamura ${ }^{\dagger}$

あらまし サブバンド符号化において各サブバンド信号の振幅分布は一般化ガウス分布でよく近 似できること，および画像やサブバンドによって分布形状が大きく変動することを示す．信号振幅 分布の変動に適応する量子化器を提案し, シミュレーションにより有効性を示す.

\section{1. まえがき}

近年，画像符号化において DCTに代わる符号化方式 としてサブバンド符号化の研究が盛んになってきてい る.サブバンド符号化の性能に影響する要因としては分 割・合成フィルタの種類と量子化器が挙げられる. 前者 に関しては，直交ミラーフィルタ $(\mathrm{QMF})^{1) 2}$, ウェー ブレット変換角4) , SSKF (Symmetric Short Kernel Filter) ${ }^{5)}$ 等について多くの研究が行われている. 後者 の量子化器の性能はいかに信号振幅分布に適合した量 子化器を設計するかに依存する。したがって, 効率の 良い量子化を行うためには信号振幅分布を知る必要が ある。

一般には信号振幅分布の確率密度関数としてガウス 分布かラプラス分布を仮定して量子化器が設計される. サブバンド信号に関しては一般化ガウス分布で近似で きるという報告 ${ }^{4) 6}$ がある。しかし，実際の信号振幅 分布が仮定した分布と異なる場合や変動する場合には 最適な量子化器とはならない。最適な量子化を行うた
めには, 分布の変動にも適応する量子化器を用いる必 要がある。

本稿ではサブバンド信号振幅分布について調べ，一 般化ガウス分布により近似できること，また画像やサ ブバンドによって大きく変動することを示す。ささら， 信号振幅分布の変動に適応する量子化器を提案し, シ ミュレーションによってその有効性を示す.

\section{2. サブバンド信号の振幅分布}

ITU-R Rec.601 の 4:2:2 信号にフィールド単位で 3 階層の 2 次元ウェーブレット変換を行い, 図 1 に示す 10 個のサブバンドに分割する。フフル夕は Daubechies ${ }^{7)}$ の 6 タップの FIR フィルタを用いた. MPEG 評価用 画像 4 種類 (mobile \& calender, cheer girl, flower garden, football) を含む 9 種類の画像各 1 フレーム (2フィールド) の輝度信号について, DPCM で符号 化される最低域のサブバンド 0 を除いた 9 個のサブバ ンドを用いて, 合計 162 個のサブバンドの振幅分布を 調べた。信号振幅をサブバンド毎に標準偏差 $\sigma$ で正

キーワード : サブバンド符号化, ウェーブレット変換, 適応量子化, 一般化ガウス分布

1995 年 7 月 26 日, テレビジョン学会年次大会に発表

1996 年 1 月 31 日受付, 1996 年 2 月 19 日再受付

†パイオニア株式会社 総合研究所（鶴ヶ島市富士見 6-1-1, TEL 0492-87-3900)

†† パイオニア株式会社 システム開発研究所（東京都大田区大森西 4-15-5, TEL 03-3763-2111)

† Corporate Research and Development Lab., Pioneer Electronic Corporation (6-1-1, Fujimi, Turugashima-shi, Saitama 350-02, Japan) †† Industrial AV Systems R \& D Lab., Pioneer Electronic Corporation (4-15-5, Oomori-Nishi, Oota-ku, Tokyo 143, Japan) 


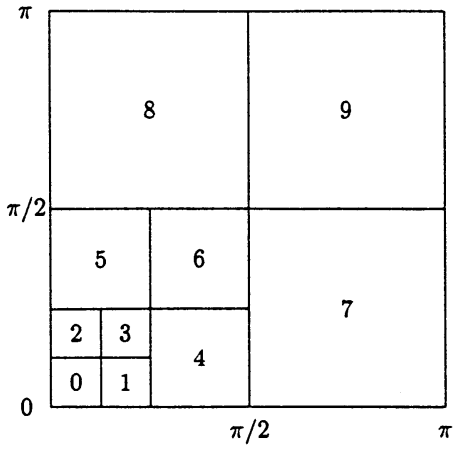

図 1 サブバンド分割

Subband decomposition.

規化し， -6.0 から 6.0 まで 0.1 ステップでヒストグ ラム $H\left(x_{i}\right)$ を求めた。標準偏差 $\sigma$ の一般化ガウス分 布 $p_{\beta}(x)$ は $\beta$ をパラメータとして次のように与えら れる。

$$
p_{\beta}(x)=\frac{\beta \gamma}{2 \Gamma(1 / \beta)} \exp \left(-|\gamma x|^{\beta}\right)
$$

ここで

$$
\gamma=\sigma^{-1}\left[\frac{\Gamma(3 / \beta)}{\Gamma(1 / \beta)}\right]^{1 / 2}
$$

$\Gamma(x)$ はガンマ関数である. $\beta=1.0$ のときはラプラス 分布, $\beta=2.0$ のときはガウス分布になる. $p_{\beta}(x)$ を $x_{i} \pm 0.05$ の区間で積分したものを

$$
\begin{aligned}
& P_{\beta}\left(x_{i}\right)=\int_{x_{i}-0.05}^{x_{i}+0.05} p_{\beta}(x) d x \\
& \text { for } x_{i}=-6.0,-5.9, \cdots, 5.9,6.0
\end{aligned}
$$

と表す．ヒストグラム $H\left(x_{i}\right)$ を最も良く近似する一 般化ガウス分布の $\beta$ を求めるために， $\chi^{2}$ 適合度検定 における

$$
\chi^{2}=\sum_{\substack{x_{i}=-6.0 \\ 0.1 \text { step }}}^{6.0} \frac{\left[H\left(x_{i}\right)-n P_{\beta}\left(x_{i}\right)\right]^{2}}{n P_{\beta}\left(x_{i}\right)}
$$

を最小とする $\beta$ を求めた。ここで, $n$ は各サブバ ンドのサンプル数である．ただし，分布の両側では $n P_{\beta}\left(x_{i}\right) \geqq 5$ の条件を満足するように複数の区間を結 合した.

図 2 に $\beta$ の頻度分布を示す. $\beta$ は 0.2 から 1.9 の広 い範囲にわたって分布しており，画像やサブバンドに よって大きく変動する. 図 3 に一般化ガウス分布に よる近似の程度を示す. 点はサブバンド信号の振幅分 布，実線はそれを近似する一般化ガウス分布である。

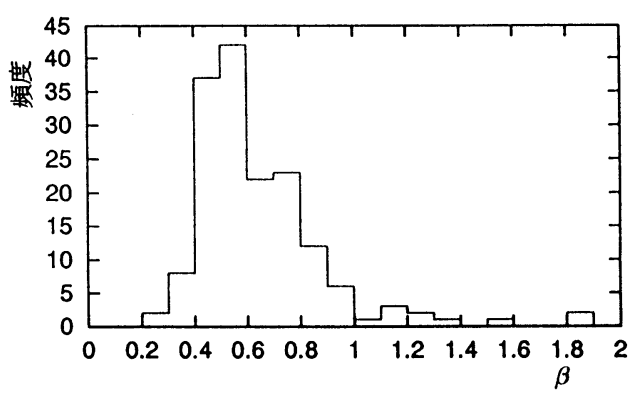

図 $2 \beta$ の頻度分布

Distribution of $\beta$.

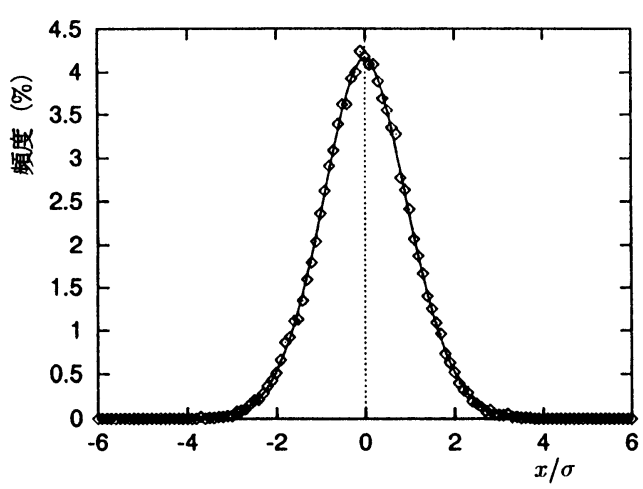

(a) 最良近似 $(\beta=1.84)$

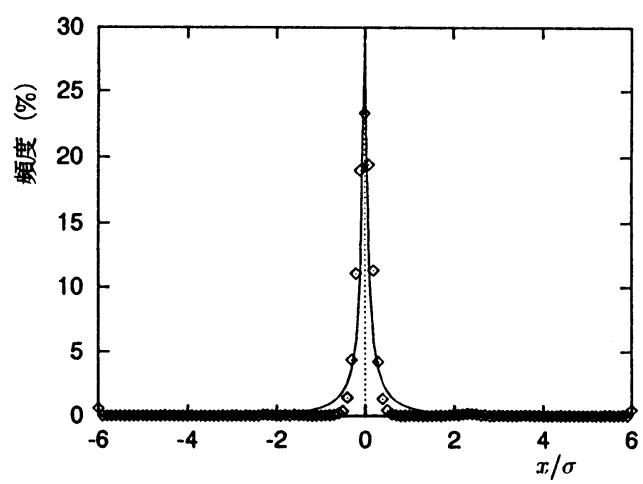

(b) 最悪近似 $(\beta=0.34)$

図 3 サブバンド信号振幅分布の一般化ガウス分布による 近似

Amplitude distributions of subband signals and their approximations by Generalized Gaussian Distribution.

(a) Best approximation, (b) Worst approximation.

図 3 (a) は最も近似が良い場合, 図 3 (b) は最も悪い場 合である。この図から振幅分布は一般化ガウス分布で よく近似できることがわかる。 


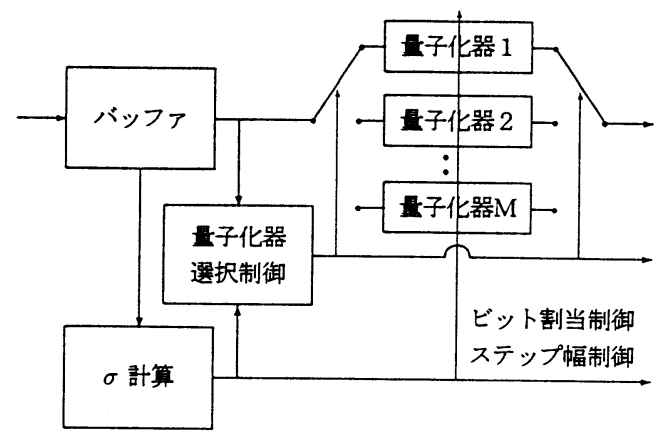

図 4 適応量子化器 Adaptive quantizer.

\section{3. 適応量子化器}

\section{1 適応量子化器の構成}

図 4 に適応量子化器の構成を示す. 量子化器 1 から $\mathrm{M}$ は平均 0 , 標準偏差 1 で $\beta$ の異なる一般化ガウス 分布に対して設計された $\mathrm{Max}^{8)}$ の非一様量子化器であ る.サブバンド毎に標準偏差 $\sigma$ が計算されて, 量子 化器選択制御，ビット割り当て制御，量子化ステップ 幅制御に用いられる. 後述する量子化器選択制御によ り複数の量子化器のひとつが選択され量子化が行われ る. 選択された量子化器のインデックス, ビット割り 当て情報, 標準偏差（スケールファクタ）はサイド情 報として送られる。

\section{2 量子化器設計に用いる $\beta$ の選定}

信号の振幅分布の変動に適応するためには多くの量 子化器を用いればよいが, 一方, ハード規模の点から は量子化器の数はなるべく少ない方が望ましい. 少数 の量子化器で振幅分布の変動に適応するために, 量子 化器の設計に用いる $\beta$ の選定について考察する.

信号振幅分布の $\beta$ を $\beta_{S}$, 量子化器設計に用いる分 布の $\beta$ を $\beta_{Q}$ とすると, $\beta_{Q}=\beta_{S}$ のときに最大の $\mathrm{SNR}$ が得られ， $\beta_{Q}$ が $\beta_{S}$ と異なると SNR が低下す る.そこで, $\beta$ のミスマッチによる SNR の低下量を 求めた。

$\beta_{Q}$ の分布 $p_{\beta_{Q}}(x)$ に対して設計した量子化境界を $x_{i}^{\left(\beta_{Q}\right)}$, 量子化代表值を $y_{i}^{\left(\beta_{Q}\right)}$ とし, 量子化される信 号の振幅分布を $p_{\beta_{S}}(x)$ とすると, 量子化ノイズのパ ワー $D$ と SNRは

$$
D=\sum_{i=1}^{N} \int_{x_{i}^{\left(\beta_{Q}\right)}}^{x_{i+1}^{\left(\beta_{Q}\right)}}\left(x-y_{i}^{\left(\beta_{Q}\right)}\right)^{2} p_{\beta_{S}}(x) d x
$$

$$
\mathrm{SNR}=-10 \log D
$$

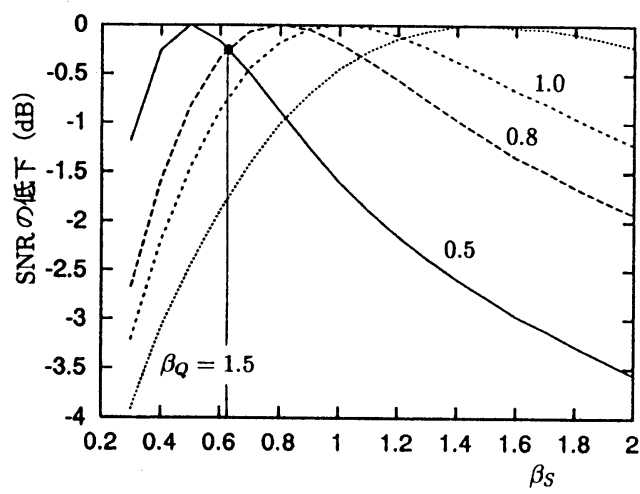

(a) $N=7$

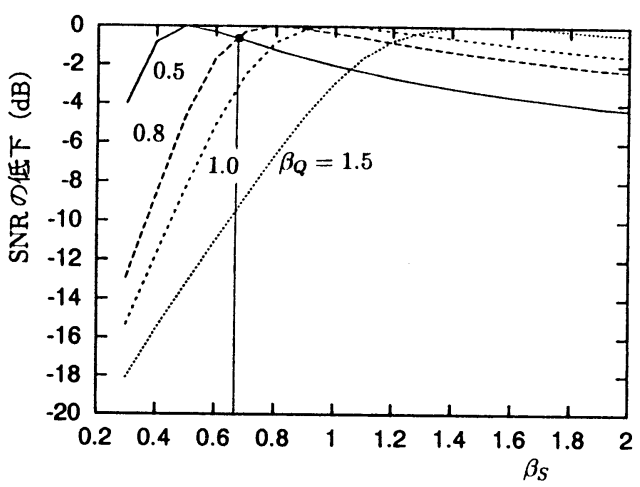

(b) $N=63$

図 $5 \beta$ のミスマッチによるSNR の低下 Decrease in SNR by mismatch of $\beta$. (a) $N=7$, (b) $N=63$.

で与えられる。ここで $N$ は量子化ステップ数である. 図 5 は $\beta_{Q}$ が $0.5,0.8,1.0,1.5$ の 4 種類の量子化器 で $\beta_{S}$ の分布を量子化したときの SNRの低下量を示 す. 図 5 (a) が $N=7$, (b) が $N=63$ の場合である. $\beta_{S}$ が $\beta_{Q}$ より大きい場合は SNR の低下は少ないが, $\beta_{S}$ が $\beta_{Q}$ より小さくなると SNR は急激に低下する. したがって， $\beta_{Q}$ は小さめに選定するのがよい. 図 2 に示されるように，サブバンド信号の $\beta$ はほとんど が 0.4 から 1.0 の範囲にあるので，この範囲での SNR の低下を $1.0 \mathrm{~dB}$ 以内に抑えるためには, $\beta_{Q}=0.5$ と $\beta_{Q}=0.8$ の 2 つ量子化器を適応的に切り換えれば よい.

\section{3 量子化器切換制御}

標準偏差で正規化した信号振幅分布は, 平均 0 , 標 準偏差 1 の一般化ガウス分布で近似できる。したがっ て，振幅が 0 近傍に存在する割合から $\beta$ が推定できる と考えられる. 図 6 は横軸に各サブバンド信号の $\beta$, 


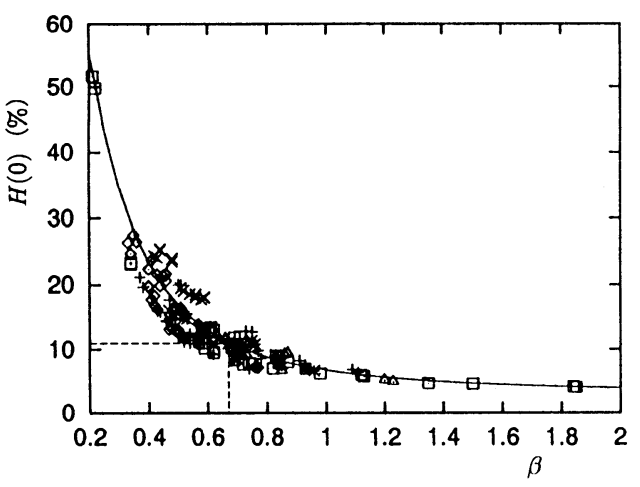

図 $6 \beta$ と $H(0)$ の関係 $H(0)$ as a function of $\beta$.

縦軸に振幅が $0 \pm 0.05 \sigma$ に存在する割合 $H(0) （ \%)$ をプロットしたものである．図中の実線は一般化ガウ ス分布に対する $0 \pm 0.05$ 内の存在割合 $P_{\beta}(0)$ を $\beta$ の 関数として示したものである. 各点は曲線に適合して いることから，0 近傍の割合 $H(0)$ から $\beta$ が推定可能 であり, $H(0)$ を量子化器切換制御に利用できる.

量子化器の切換の閾值 $T$ は, 図 5 において $\beta_{Q}=0.5$ と $\beta_{Q}=0.8$ の曲線が交差する点 $\beta=0.67$ に相当する $T=P_{\beta=0.67}(0)=11 \%$ に設定する.$H(0)$ が $11 \%$ 以 上の場合は $\beta_{Q}=0.5$ の量子化器を, $11 \%$ 未満の場合 は $\beta_{Q}=0.8$ の量子化器を選択する.

\section{4. 量子化器の評価}

ウェーブレット変換によるサブバンド符号化に，分 布形状に適応する量子化器を用いて, その効果を評価 した. 各サブバンド信号は標準偏差に応じて適応的に 決められるビット数で量子化される. 量子化器出力は 0 ランとレベルの組み合わせにより 2 次元ハフマン符 号化される. 量子化器は以下の 3 種類である.

量子化器 $\mathrm{A}(\mathrm{QA})$ ： ラプラス分布 $\left(\beta_{Q}=1.0\right)$ 固定 量子化器 $\mathrm{B}(\mathrm{QB}): \beta_{Q}=0.4, \beta_{Q}=0.7$ 適応切換 $(T=14 \%)$

量子化器 $\mathrm{C}(\mathrm{QC}): \beta_{Q}=0.5, \beta_{Q}=0.8$ 適応切換 $(T=11 \%)$

符号化結果は SNR

$$
\mathrm{SNR}=20 \log _{10} \frac{255}{\sigma_{n}} \quad(\mathrm{~dB})
$$

とビットレート $(\mathrm{Mb} / \mathrm{s})$ で評価する.ここで $\sigma_{n}$ は量 子化ノイズの標準偏差である.

図 7 は各種画像 1 フレーム分を符号化した結果を示

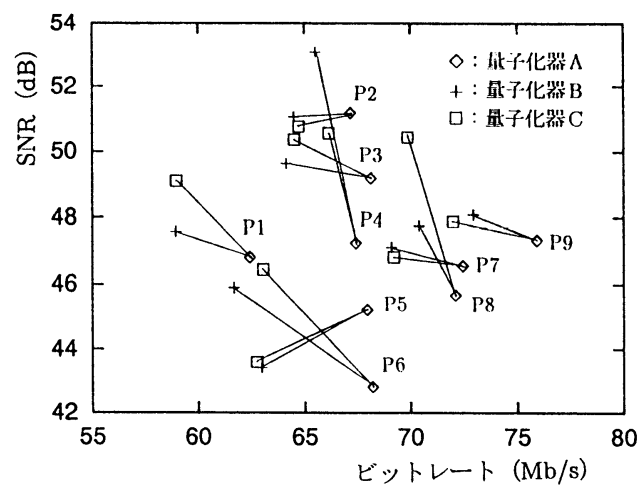

図 7 量子化器の性能比較 $(\diamond:$ 量子化器 $\mathrm{A}$, + : 量子化器 $B, \square:$ 量子化器 $C$ )

Performance of quantizers $(\diamond: \mathrm{QA},+: \mathrm{QB}, \square: \mathrm{QC})$.

す。横軸はビットレート, 縦軸は SNRである。した がって, 左上にあるほど望ましい。っは量子化器 $\mathrm{A}$, 十 は量子化器 $\mathrm{B}$, 口 は量子化器 $\mathrm{C}$ を表す. P1 から P9 は画像の番号である.P2 と P5 を除き, 適応量子化器 を用いることにより, ラプラス分布の固定量子化器を 用いた場合に比べて SNR が向上しビットレートが減 少しており, 有効性が示される. 量子化器 $\mathrm{B}$ と C の比 較では若干量子化器 $\mathrm{C}$ の方が良い.

\section{5.むす び}

一般化ガウス分布の $\beta$ をパラメータとして, 異なる 分布に対して設計した複数の量子化器を適応的に切り 換える適応量子化について検討した.

まず画像のサブバンド信号の振幅分布を測定して, 絵柄やサブバンドによって分布形状が大きく変動する ことから, 分布形状に適応する量子化の必要性を示し た。また，分布は一般化ガウス分布によって精度よく 近似できることを明らかにした。

ついで, 量子化器設計に用いた分布 $\left(\beta_{Q}\right)$ と信号分 布 $\left(\beta_{S}\right)$ のミスマッチによる SNR の低下を計算し, $\beta_{S}<\beta_{Q}$ の範囲で SNR が急激に低下することを示し た. ほとんどのサブバンド信号の分布は $0.4<\beta<1.0$ の範囲に入るので, この範囲で $\beta$ のミスマッチによ る SNR 低下を $1.0 \mathrm{~dB}$ 以内に抑えるためには, 量子化 器は 2 つあれば充分である。また, 量子化器切換制御 は信号振幅分布の 0 近傍の割合によって行うことがで きる。

最後にウェーブレット変換によるサブバンド符号化 に提案する適応量子化器を用いた結果, SNR の向上 とビットレートの低減がはかられ, 有効性が示された。 


\section{〔参考 文 献〕}

1) J.D. Johnston: "A Filter Family Designed for Use in Quadrature Mirror Filter Banks”, IEEE Proc. Int. Conf. ASSP, pp.291-294 (Apr. 1980)

2) J.W. Woods, S.D. O'Neil: "Subband Coding of Images", IEEE Trans. Acoust., Speech, Signal Process., 34, 5, pp.1278-1288 (Oct. 1986)

3) S.G. Mallat: "A Theory for Multiresolution Signal Decomposition: The Wavelet Representation", IEEE Trans. Pattern Anal. \& Mach. Intell., 11, 7, pp.674-693 (July 1989)

4) M. Antonini, M. Barland, P. Mathieu, I. Daubechies: "Image Coding Using Wavelet Transform", IEEE Trans. Im- age Process., 1, 2, pp.205-220 (Apr. 1992)

5) D.L. Gall: "Sub-band Coding of Digital Images Using Symmetric Short Kernel Filters and Arithmetic Coding Techniques", IEEE Proc. Int. Conf. ASSP, pp.761-764 (Apr. 1988)

6）樋口，源川，小松, 斎藤：“超高精細画像のサブバンド符号 化に関する一検討（その1)一高域サブバンド信号の量子化の 改善-”, 平 4 信学春全大, D-315

7) I. Daubechies: "Orthonormal Bases of Compactly Sup. ported Wavelet", Commun. Pure Applied Math., 41, pp.909-996 (Nov. 1988)

8) J. Max: "Quantizing for Minimum Distortion", IRE Trans. Inf. Theory, 6, pp.7-12 (Mar. 1960)
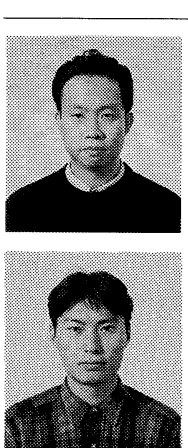

架好橋努 1988 年, 東京理科大学工学 部電気工学科卒業. 同年, パイオニア (株)に 入社. 同社所沢技術研究所にて CD-ROM の デコード IC の開発, $\alpha$ ビジョンエンコーダ の開発に従事. 現在, 同社総合研究所におい て画像符号化の研究に従事.

村らこ越告う 1993 年, 東北大学大学院工 学研究科電子工学専攻修士課程修了. 同年, パイオニア (株)に入社. 同社総合研究所にお いて画像符号化の研究に従事, 現在に至る.

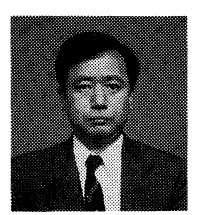

吉田賢 1973 年, 東京大学工学部電 気工学科卒業。翌年, パイオニア (株) に入社。 主にディジタルオーディオ, ディジタルビデ 才, 画像符号化の研究開発に従事. 正会員.

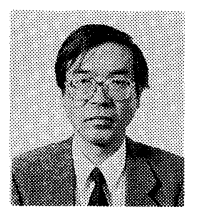

こまむら みつゃ

駒村 光弥 1967 年, 東北大学工学部電 気工学科卒業. 1973 年, 同大学院博士課程修 了. 同年, パイオニア(株)に入社. 心理音響, オーディオ符号化, 画像符号化の研究に従事. 工学博士. 